\title{
Article \\ Monitoring of Land Subsidence and Ground Fissure Activity within the Su-Xi-Chang Area Based on Time-Series InSAR
}

\author{
Chengsheng Yang ${ }^{1}$, Sen $\mathrm{Lv}^{1}{ }^{1 *}$, Zuhang Hou ${ }^{1}$, Qin Zhang ${ }^{1}$, Tao $\mathrm{Li}^{2}$ and Chaoying Zhao ${ }^{1} \mathbb{C}$ \\ 1 College of Geology Engineering and Geomatics, Chang'an University, Xi'an 710054, China; \\ yangchengsheng@chd.edu.cn (C.Y.); 2020226043@chd.edu.cn (Z.H.); dczhangq@chd.edu.cn (Q.Z.); \\ cyzhao@chd.edu.cn (C.Z.) \\ 2 Land Satellite Remote Sensing Application Center, Beijing 100048, China; lit@lasac.cn \\ * Correspondence: 2020226012@chd.edu.cn; Tel.: +86-29-8233-9261
}

Citation: Yang, C.; Lv, S.; Hou, Z.; Zhang, Q.; Li, T.; Zhao, C. Monitoring of Land Subsidence and Ground Fissure Activity within the Su-Xi-Chang Area Based on Time-Series InSAR. Remote Sens. 2022 14, 903. https://doi.org/10.3390/ rs14040903

Academic Editor: Nicola Casagli

Received: 29 December 2021

Accepted: 9 February 2022

Published: 14 February 2022

Publisher's Note: MDPI stays neutral with regard to jurisdictional claims in published maps and institutional affiliations.

Copyright: (c) 2022 by the authors Licensee MDPI, Basel, Switzerland. This article is an open access article distributed under the terms and conditions of the Creative Commons Attribution (CC BY) license (https:// creativecommons.org/licenses/by/ $4.0 /)$.

\begin{abstract}
Serious land subsidence and ground fissure (GF) disasters have brought huge economic losses to the $\mathrm{Su}-\mathrm{Xi}$-Chang area (China) and threatened the safety of its residents. To better understand the development of these disasters, it is urgent to carry out long-term and large-scale deformation monitoring in this region. In this study, based on time-series interferometric synthetic aperture radar (InSAR) technology, ground deformation characteristics were obtained at different periods. Meanwhile, Fast Lagrangian Analysis of Continua in Three Dimensions (FLAC3D) version 5.00 was used to study the stress, seepage field, and displacement changes in the soil layers caused by pumping activities at the bedrock bulge. The results showed that three subsidence centers were located in Suzhou, Wuxi, and Changzhou from 2007 to 2010. The ground fissures in Guangming village had obvious differential settlements and intense activities. The land subsidence in the Su-Xi-Chang area was under control from 2018 to 2021, while there was a relative rebound in most areas. Combined with numerical simulation and geological data, we demonstrated that pumping activities would accelerate and intensify the land subsidence process, and differential subsidence was prone to occur at the buried hill, which in turn led to the formation of ground fissures. By comparing the characteristics of ground deformation in different periods, it was proven that banning groundwater exploitation is an effective measure for preventing and controlling such disasters.
\end{abstract}

Keywords: Su-Xi-Chang area; InSAR time-series; ground fissure; land subsidence; FLAC3D

\section{Introduction}

Overexploitation of groundwater resources may result in compression of aquifer systems (aquifers and permeable aquifers), which causes rapid land subsidence [1]. Many major cities around the world are facing such geological disasters due to the excessive extraction of groundwater, such as central Mexico, Las Vegas in the USA, and the United Arab Emirates [2-4]. Moreover, ground subsidence disasters are often accompanied by the formation and development of ground fissures (GFs). A GF is a type of geological disaster that occurs following the fracture of rock and soil [5,6]. Ground subsidence disasters pose an enormous threat to underground engineering, surface construction, and the safety and properties of human life [7-9]. Land subsidence in coastal areas or around lakes is also prone to causing disasters such as waterlogging and flooding due to the loss of elevation $[10,11]$.

Previous investigations have shown that at least 3000 GFs are distributed throughout the Northern China Plain, and approximately $80 \%$ of the GFs are non-structural $[6,12,13]$. In some regions, although land subsidence disasters have been alleviated to a certain extent owing to natural and artificial groundwater recharges, the trend has not yet reversed because of excessive groundwater extraction [14].

The mechanisms of land subsidence can be divided into two categories: the tectonic control type and non-tectonic control type [6]. Tectonic factors such as faults, earthquakes, 
basements, basins and sediments affect the formation and development of surface deformation to a great extent, while non-tectonic factors $[15,16]$ such as the over-exploitation of groundwater, rainfall conditions and climate also have a great impact on the breeding process of land subsidence. The inducing factors of ground fissures can be divided into three categories $[5,9,16,17]$ - they are: (1) internal dynamic action, such as fault creep, earthquakes and volcanic eruptions; (2) extraction of underground fluids, such as water, oil and gas; (3) semiarid climates. Based on the ground fissures found in China, the main causes of such disasters are mainly tectonic activities and groundwater exploitation.

To better understand the internal relationship between land subsidence and GFs in the study area, a wide range of ground subsidence characteristics must be investigated. Many methods can be used for land subsidence monitoring, such as: (1) taking measurements with standard land surveying methods (precise leveling, total stations or global navigation satellite systems (GNSS)) over the established stable benchmarks at different times at the same site, while obtaining the elevation differences; (2) making comparisons of measurements from borehole extensometers; (3) making comparisons of elevations from light detection and ranging (LIDAR) data acquired at different times or by using other elevation datasets [11,17-20]. In addition to mapping technology for directly obtaining surface deformation, some commonly used technologies in engineering exploration are also used to study land subsidence and ground fissure disasters, such as pore water pressure gauges [17], convergence measurements, layered standards and distributed optical fibers [21], which can measure changes in the strata below the surface. However, these technologies generally have the characteristics of a high cost, a large workload in the field, and poor continuity of deformation.

The Su-Xi-Chang area mainly includes the Suzhou, Wuxi, and Changzhou cities of China (Figure 1), which-especially Jiangyin City (subordinate to Wuxi)—are typical areas with land subsidence and ground fissure phenomena. It lies in the southern part of Jiangsu Province, around the lower reaches of the Yangtze River, and east of Shanghai City (Figure 1). The Su-Xi-Chang region has various types of groundwater, complex burial conditions, and an uneven distribution of groundwater, with obvious regional characteristics. Pore water is the main groundwater type in unconsolidated materials in plain areas [22,23]. The aquifers are partitioned into phreatic aquifers and confined aquifers-marked as I, II, and III, respectively, from top to bottom based on their genesis, ages, burial distributions, hydraulic connections, and hydro-chemical characteristics [24,25]. Confined aquifer II is the main groundwater exploitation layer, consisting of Middle Pleistocene loam, medium coarse sand, fine sand, sandy loam, coarse sand with pebbles and gravel $[14,22,24]$.

Due to the rapid development of industry and the large water demand for residential daily life, as well as irrigated agriculture, groundwater is consumed quickly and in large quantities, and land subsidence disasters began to emerge in the Su-Xi-Chang region in the early 1960s [26,27]. Over the next few decades, the groundwater level has continued to decrease, with a wider range of uneven land subsidence. The rapid development of land subsidence has brought on the discovery of several GFs [22]. The government has made considerable efforts to mitigate regional land subsidence since 2005, including prohibiting groundwater withdrawal. Currently, the land subsidence rate in the study area has declined to less than $10 \mathrm{~mm} /$ year in most areas [25,26].

GFs such as those in Yangshuli (YSL), Guangming village (GM), and Wuxi City are the most typical, appearing in early 1998 and further developing after 2000. In the next few years, the inclination of the paddy fields increased, forcing villagers to level the paddy fields every year and divide the paddy fields into small pieces for cultivation [28]. With the development of the JY subsidence field, the occurrence of GF disasters in the region peaked after 2007. Although the groundwater ban has been implemented for a long time, the ground rebound has a hysteresis effect. Thus, the ground rebound rate is extremely slow. It was not until surface monitoring in recent years that a tiny rebound phenomenon was observed [25]. 

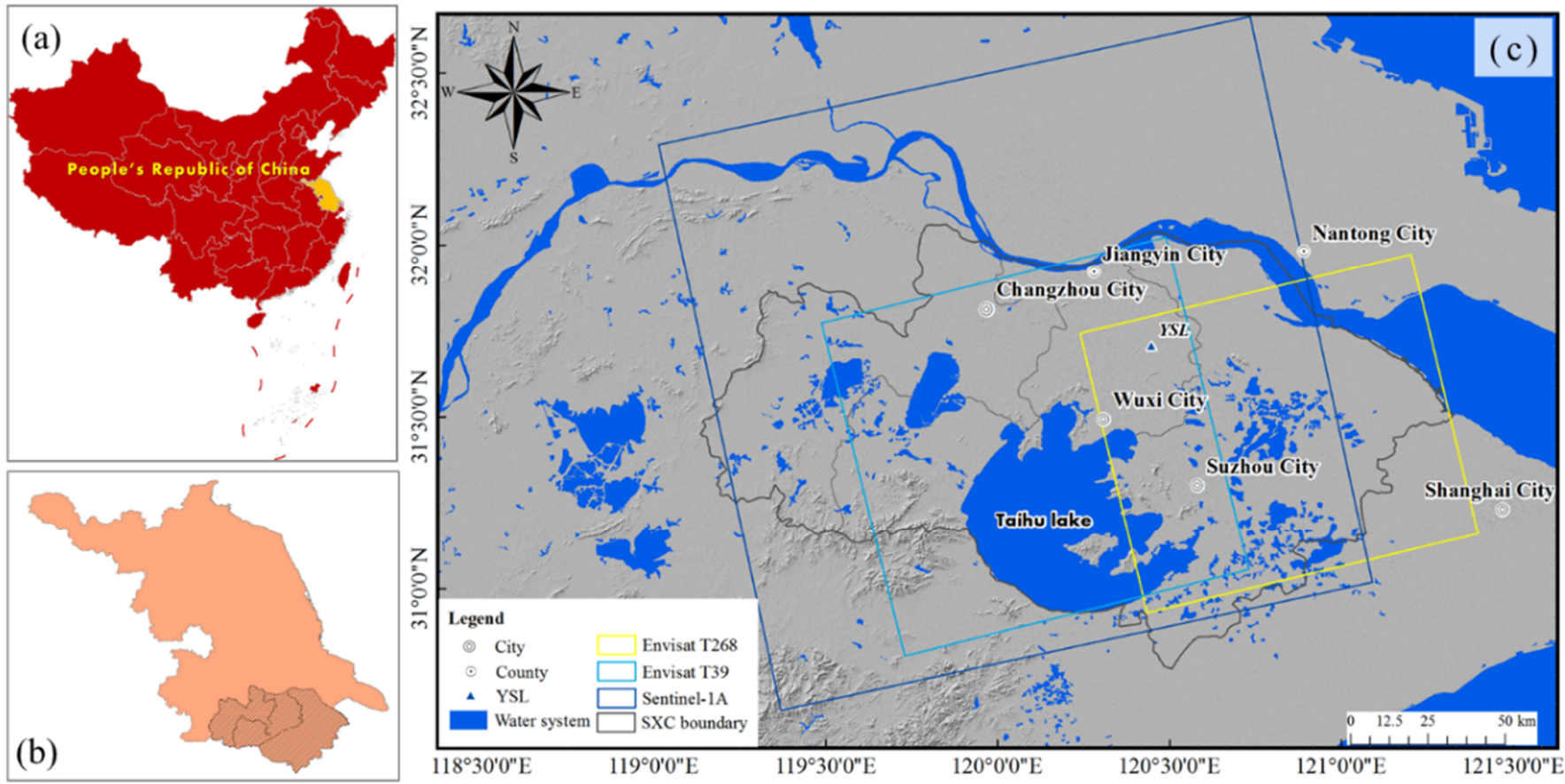

Figure 1. Geographical location of Su-Xi-Chang area. (a) Geographical position of Jiangsu Province in China. (b) Geographical location of Su-Xi-Chang area in Jiangsu Province. (c) SAR image coverage. YSL stands for Yangshuli where the GF disaster occurred.

As a space-to-earth observation technology, interferometric synthetic aperture radar (InSAR) has the advantage of obtaining surface deformations over a large area with high precision. Combined with geological data, the corresponding relationship between the surface deformation information obtained by InSAR and the geological background can be obtained, such as the temporal and spatial variation relationship between the deformation funnel and the fluctuation of bedrock.

In this study, land subsidence and GF activities in the Su-Xi-Chang area were monitored using time-series InSAR technology based on SAR images from different periods. To study surface deformation from 2007 to 2010, we used two sets of Envisat advanced synthetic aperture radar (ASAR) images from different orbits: Envisat T39 and T268. The surface deformation of this area was observed based on Sentiel-1A images from 2018 to 2021. The Stanford method for persistent scatterers (StaMPS) was used to process SAR data [29]. We then analyzed and discussed the deformation information of the Su-Xi-Chang region. Fast Lagrangian Analysis of Continua in Three Dimensions (FLAC3D) software was used to simulate the surface deformation caused by pumping activities to verify the causes of land subsidence and GF disasters. Our research can support the government's decision making in response to disasters and the effective allocation of resource development and provide a reference for studying surface subsidence and GF disasters.

\section{Research Status}

Since land subsidence and GF disasters have appeared in this region, scholars have done a lot of work to analyze the mechanisms of land subsidence and ground fissure, including model experiments, numerical simulations and data measurements. Bu et al. analyzed the developmental process of land subsidence with pumping in the Su-Xi-Chang area [24]. Wu et al. observed the difference in land subsidence on both sides of the ground fissure through leveling, and found that the uneven distribution of loose layers determined the uneven land subsidence through geological drilling and a controllable source geodetic audio sounding method [22]. Using distributed fiber optical sensing technologies and microstructure analysis, Gu et al. found that the larger the proportion of soil voids, the 
easier it is to produce land subsidence [26]. Gu conducted a pumping experiment by analyzing a ground fissure in a buried hill area via a macro model experiment, and he found that the more the groundwater level drops, the more serious are the land subsidence and ground fissures that are likely to occur [28]. Through leveling, groundwater head measurements and a borehole extensometer, Wang et al. found that there was a time lag between land subsidence or uplift and changes in groundwater level in the Su-Xi-Chang area [25], and she analyzed the Changjing ground fissure located in Jiangyin City [30]. Many studies have surmised that the development of GFs is affected by various factors, such as bedrock undulation, heterogeneity of the Quaternary strata, groundwater overextraction and differential land subsidence [27,31-33]. Chen et al. found that excessive extraction of groundwater is the principal factor in the occurrence of land subsidence disasters. As the depth of the strata increases, the compression of the soil layer caused by the weight of the soil body increases, and the settlement caused by the upper loads increases with increases in the upper load intensity; this phenomenon was verified using a column element settlement model [34]. Liu obtained the same conclusion using a numerical simulation method based on the numerical simulation software MatDEM [35].

At present, the rebound phenomenon of the ground is mainly explained by measured data and model experiments. Hu concluded from the measured data that the effective stress in the stratum disappeared owing to the sharp rise in the groundwater level, the elastic deformation in the stratum was partially restored owing to the unloading effect, and the ground rebounded [14]. Wang et al. also confirmed the existence of ground rebound through measured data [25]. Xu et al. confirmed that land subsidence and GF disasters caused by groundwater extraction are reversible processes by building physical models and related experimental systems in the laboratory [13].

Predecessors have done a lot of research on the disaster mechanisms in this area, but there is a lack of corresponding research results on the developmental process of disasters and the changes in surface deformation after groundwater mining prohibition. For example, the measured data of these studies are only based on individual points and there is a lack of deformation monitoring of the entire area in previous studies. Therefore, it is difficult to conduct a more refined analysis and description of surface deformation. To better understand the causes and development of land subsidence and the formation of GFs, we used different bands of synthetic aperture radar (SAR) images to study the surface deformation of this area-namely, Envisat ASAR and Sentinel 1A—using time-series InSAR technology.

\section{Methods and Data Processing}

\subsection{Methods}

The differential InSAR technology used for land surface deformation monitoring is subject to various factors such as the residual phase of the look angle error, satellite orbit error, decoherence, phase unwrapping error, digital surface model (DSM) error and atmospheric delay error [36,37]. Among the factors mentioned above, the accuracy and precision of InSAR technology for monitoring surface deformation are mainly limited by coherence and atmospheric delay errors. By utilizing permanent scatterer (PS) InSAR technology, the aforementioned errors can be effectively reduced.

The PS-InSAR method is based on PS points, which exhibit stable scattering characteristics. The PS points were obtained by analyzing the phase and amplitude variations of the SAR data in the same region during a certain period of time. By utilizing the StaMPS method firstly provided by Hooper in 2007, slowly decorrelating filtered phase (SDFP) pixels with smaller amplitudes and relatively stable phases were selected. PS/SDFP pixels were refined using multiple iterative calculations. Based on the selected PS/SDFP pixels, deformation information can be analyzed and extracted. The number of PS points in nonurban areas can be enhanced using the StaMPS method [29]. Figure 2 shows the technical process of StaMPS technology. 


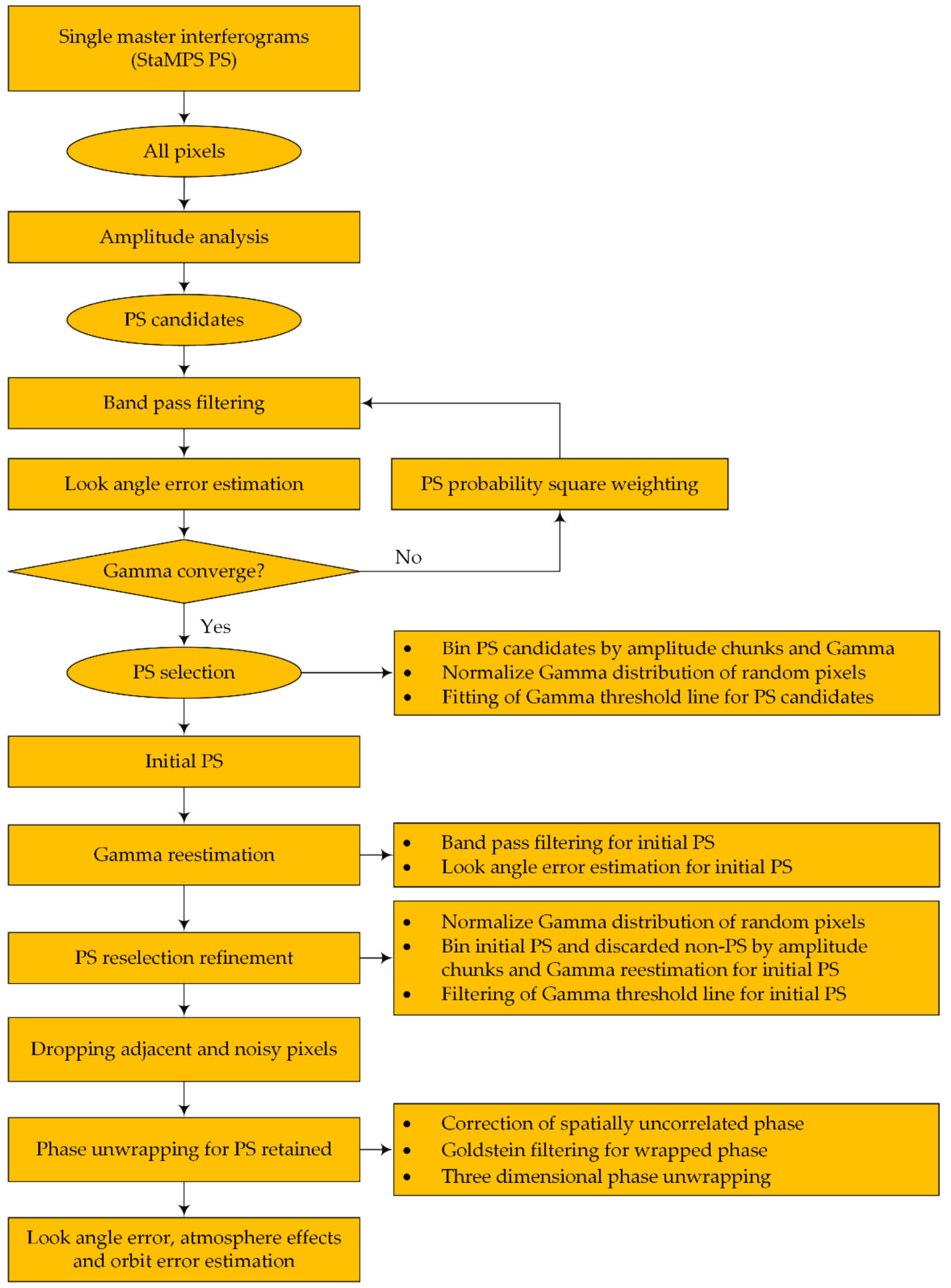

Figure 2. StaMPS technology flow chart.

However, this measurement technology based on interference points has high requirements for the phase stability of point targets in the study area. For rural areas dominated by farmland, it is difficult to obtain sufficient monitoring data. In addition, in the data processing, due to the differences in the selection of unwrapping reference points, the deformation 
results may have an overall deviation. As we analyzed the deformation characteristics on a large scale in our study, we ignored the problem of insufficient data in farmland areas. In order to solve the deviation caused by different unwrapping reference points, we set the same reference area for different orbital SAR images.

\subsection{InSAR Data Processing}

In this study, we monitored the surface deformation of two different time periods based on the data obtained from different sensors. Envisat ASAR images were used to study ground deformation from 2007 to 2010. In addition, data from Sentinel-1 were collected to observe the ground settlement from 2018 to 2021. Specific information, the number of interferograms, and the acquisition time of the main image involved in the calculation of the different sets of SAR images are listed in Table 1. The repeat orbit interferometry PACkage (ROI_PAC) was used to convert the Envisat ASAR raw images into single-look complex images [38]. Doris software V4.06 was used to produce interferograms for the Envisat ASAR images [39]. Interferograms were generated using GAMMA Remote Sensing software version 201807 for Sentinel-1 images. Time-series analysis can be utilized with a single master image, assuming that the number of SAR images is sufficient. Therefore, the ground deformation was obtained using the StaMPS PS-InSAR technique. To reduce the perpendicular and temporal baselines and Doppler difference, and considering the degree of vegetation cover, we chose the SAR images taken in the middle of the time span and taken in winter as the master image SAR images (Table 1). The distribution information of the spatiotemporal baselines of the interferograms obtained from different sensors is shown in Figure 3.

Table 1. Detailed information for the SAR images used in this study.

\begin{tabular}{llll}
\hline Sensor & Envisat T268 & Envisat T39 & Sentinel 1A (T69) \\
\hline Band & $\mathrm{C}$ & $\mathrm{C}$ & $\mathrm{C}$ \\
Orbit direction & ascending & ascending & ascending \\
Heading $\left(^{\circ}\right)$ & -13.2 & -13.2 & -12.7 \\
Incidence angle $\left(^{\circ}\right)$ & 23.2 & 23.2 & 39.3 \\
Polarization & $\mathrm{VV}$ & $\mathrm{VV}$ & $\mathrm{VV}$ \\
Number of & 21 & 23 & 42 \\
interferograms & 14 February 2009 & 29 January 2009 & 22 February 2020 \\
Master image & March 2008-February 2009 & November 2007-April 2010 & January 2019-June 2021 \\
Time span & & &
\end{tabular}
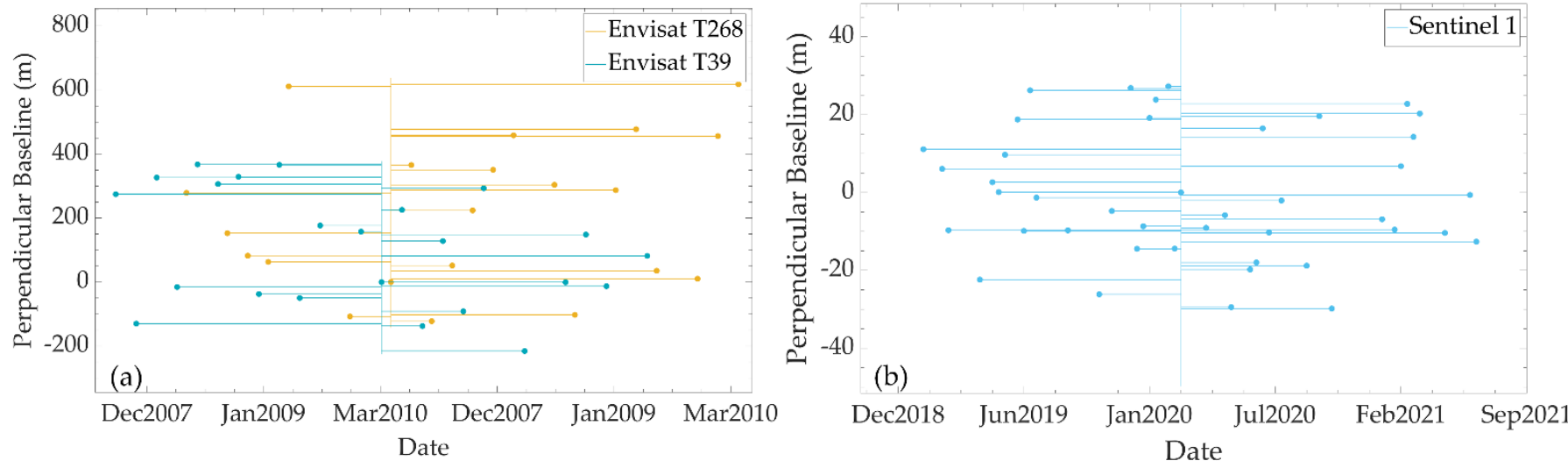

Figure 3. Space-time baseline distributions of the interferograms from the three sets of SAR images. (a) Envisat ASAR (2007-2010), (b) Sentinel 1A (2018-2021).

To subtract the terrain phase from the interference phase more accurately, a shuttle radar topography mission with $30 \mathrm{~m}$ resolution (SRTM1) was utilized. In this study, 21, 23 and 42 interferograms from Envisat T268, T39 and Sentinel-1 images, respectively, were used. Subsequently, phase iterative filtering was performed on the selected interferograms 
to optimize the DEM error. Points with phase standard deviations less than 0.8 rad were selected for the refinement of coherent points [40]. Generally, the difference in the atmospheric delay between passes has a more significant effect on the unwrapped phase quality [41]. Based on the spatial and temporal correlations of differential interferograms, this type of error caused by the atmosphere was reduced from each differential interferogram by filtering. The deformation velocity and time-series deformation information in the $\mathrm{Su}-\mathrm{Xi}$-Chang area were obtained through the decomposition of the unwrapping phase and the removal of the error phase.

\subsection{Constitutive Relationship Model}

When using FLAC3D software for numerical simulations to study the influence of pumping activities on surface deformation, it is very important to select an appropriate constitutive model to describe the mechanical response between soil particles. This model is an empirical expression of the mechanical characteristics of materials. Given the discrepancy of different material properties, to show the mechanical response of geotechnical materials with different external loads in different situations, the FLAC3D software developed 12 different models. The Mohr-Coulomb model is frequently used in geotechnical mechanics studies [42,43]; it is more appropriate for the analysis of loose and cemented granular materials [44]. We used this model in our study to obtain the variation in the geotechnical materials around the GFs under pumping activities. The physical parameters of the soil play a key role in the improvement of the simulation accuracy of stratum activity, including porosity (n), permeability coefficient (k), Young's modulus (E), Poisson's ratio (v), internal friction angle $(\mathrm{u})$, cohesion $(\mathrm{c})$, expansion angle $(\mathrm{w})$, tensile strength $(\mathrm{T})$, normal stiffness (Kn) and tangential stiffness [18]. The model analysis assists in understanding the relationship between land subsidence, ground fissure activity and pumping in this area, and provides guidance for regional groundwater exploitation.

\section{Results and Analysis}

In order to interpret the deformation information monitored by time-series InSAR, spatial analysis technology was applied, and time-series points of typical deformation area were extracted in our study. Through these analyses, the temporal and spatial characteristics of surface deformation in the study area can be clearly demonstrated. The specific research method is shown in Figure 4.

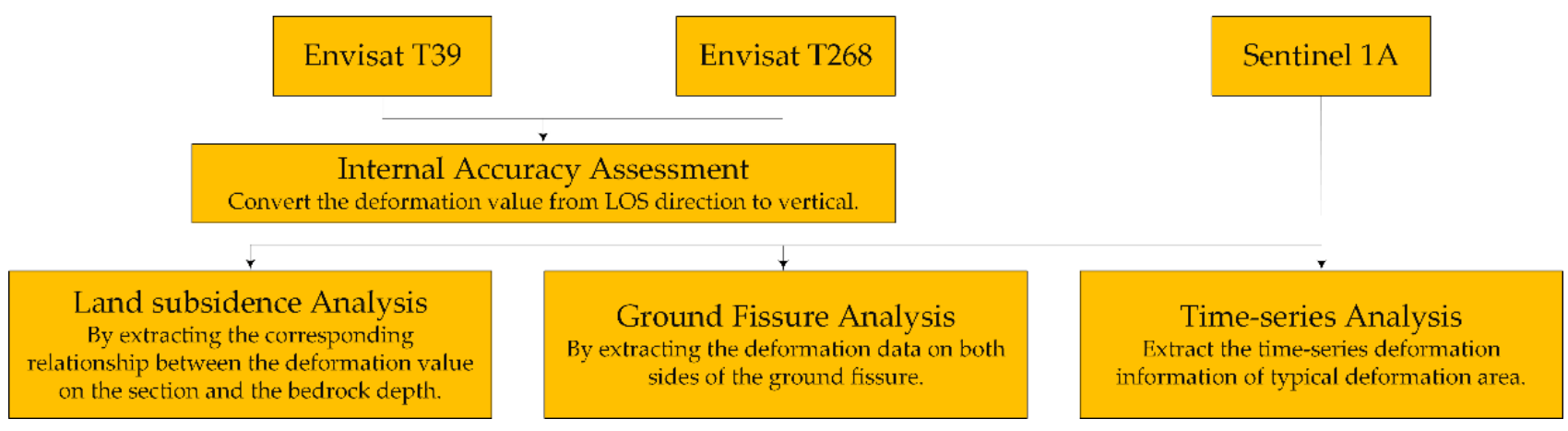

Figure 4. Flow chart of deformation field analysis.

\subsection{Results from SAR Images}

The annual deformation rates calculated from the two bands of the SAR images are shown in Figure 5a,b, which reveal the ground displacement toward or away from the sensor in the line-of-sight (LOS) by the positive or negative value of the deformation velocity, respectively. However, differences in imaging geometry parameters may influence the results, such as the resolution of SAR images, azimuth angle, and incident angle, which lead to differences in the results. Through comparison and comprehensive analysis of the 
results, we found that the southern part of JY was the main subsidence area. Therefore, we mainly demonstrate JY where severe land subsidence and GFs had occurred and continued to develop. From 2007 to 2010, the largest deformation rate was more than $20 \mathrm{~mm} /$ year, which is consistent with the results from previous research [14,22].
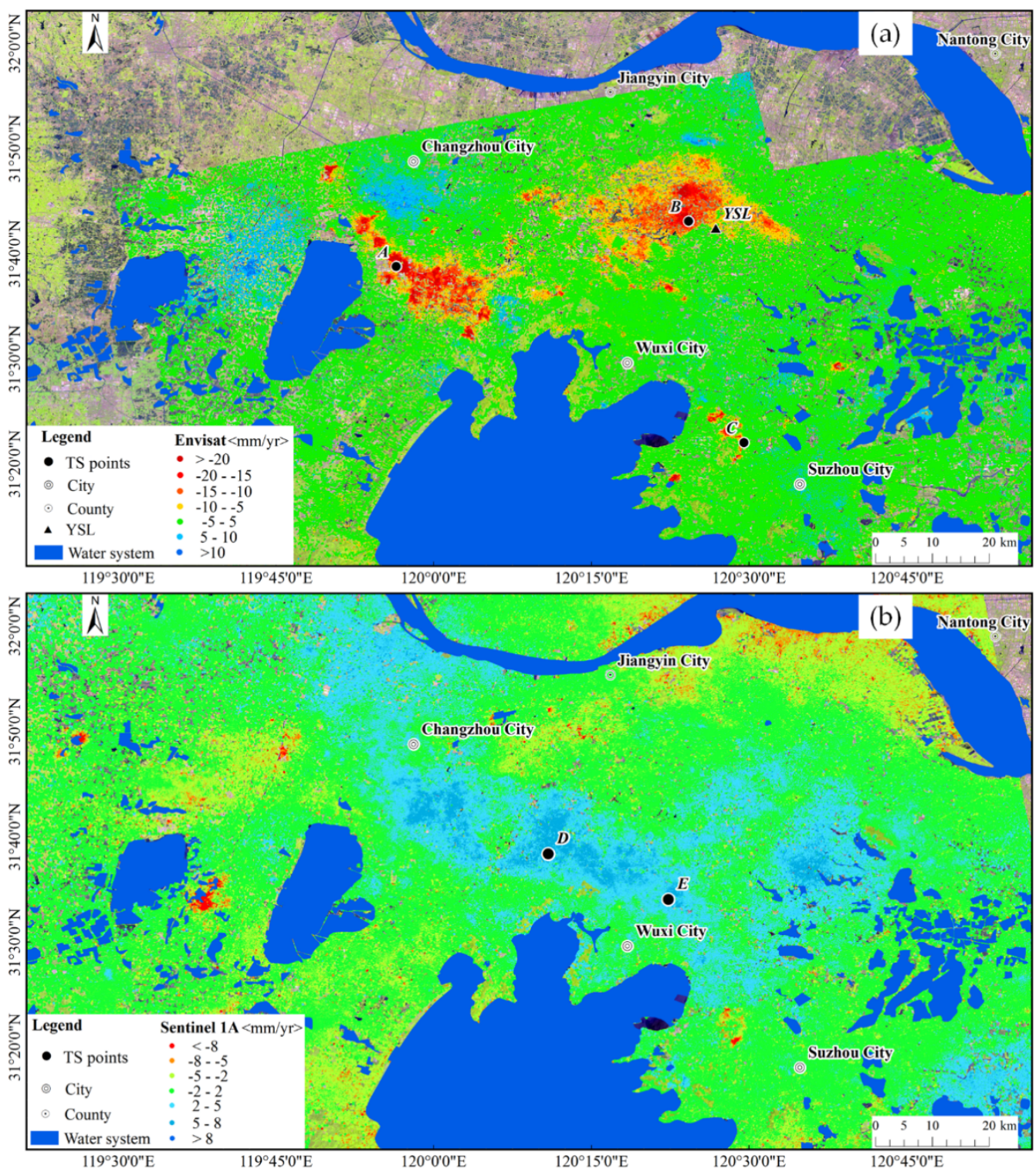

Figure 5. Su-Xi-Chang area deformation rates derived from SAR data. InSAR results inferred from (a) E nvisat T39 and Envisat T268, and (b) Sentinel 1A.

Three time-series (TS) points were selected from the subsidence regions (Wuxi, Suzhou, and Changzhou) to obtain the time-series deformation, as shown in Figures $5 \mathrm{a}$ and $6 \mathrm{a}$. From November 2007 to May 2010, point A, which is located in the settlement center of Changzhou, had a cumulative settlement of $68 \mathrm{~mm}$; point $\mathrm{B}$ was located in the settlement center of Wuxi, south of JY, with a cumulative settlement of $67 \mathrm{~mm}$; and point C was in Suzhou City, with a cumulative settlement of $45 \mathrm{~mm}$.

After examining the deformation monitoring results from 2018 to 2020 (Figure 5b), we found that land subsidence in the entire Su-Xi-Chang area was effectively controlled, and a large area of surface rebound occurred in Changzhou and Wuxi. The maximum rebound rate was approximately $10 \mathrm{~mm}$ /year. To analyze the deformation process of the ground during this period, two TS points were selected (Figure 5b); specifically, D and E, between 
Changzhou and Wuxi. The TS points showed that the surface deformation during this period slowed down, and there was a slight rebound after July each year. This may be related to an increase in rainfall and short-term groundwater supplementation (Figure 6b).
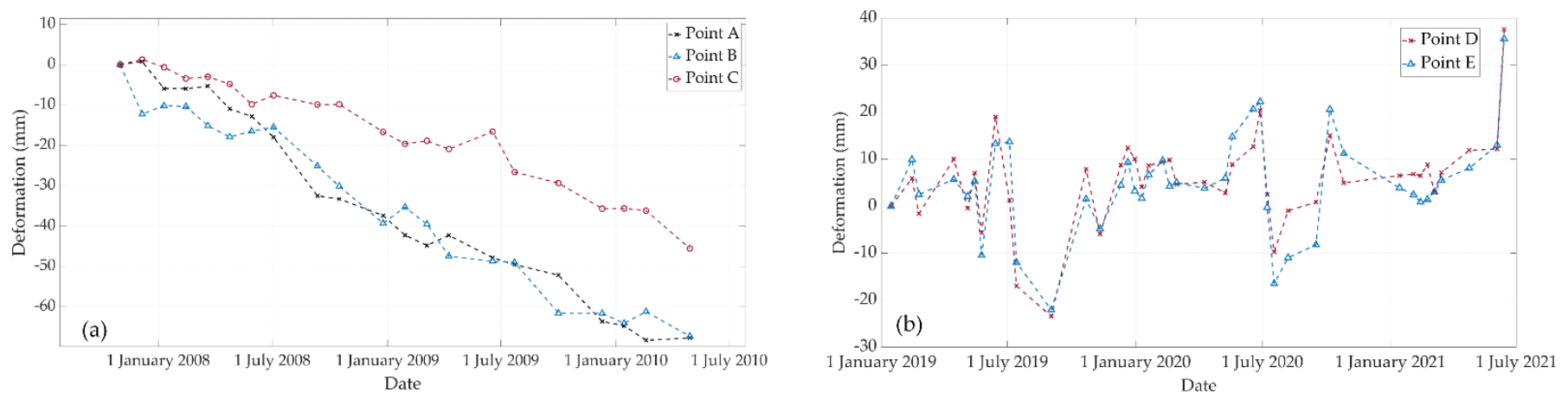

Figure 6. Time-series deformation information at the typical deformation area. (a) Obtained from Envisat T39 (Points A, B, and C are displayed in Figure 5a). (b) Obtained from Sentinel 1A (Point D and $\mathrm{E}$ are displayed in Figure $5 \mathrm{~b})$.

Since the external observation materials applied to verify the InSAR observation results are lacking, such as GNSS observation or leveling data, an internal compliance accuracy assessment is utilized to evaluate the quality of the InSAR monitoring results [44,45]. As the two sets of Envisat ASAR data obtained from different orbits are consistent over time, the monitoring results of their common areas corresponding to the same pixel are extracted and compared. Since the results of the InSAR monitoring are along the line of sight (LOS) of the sensor, the InSAR results obtained at different incidence angles differ from each other in theory [46-48]. Before comparing the two sets of data, the monitoring results must be transferred in the vertical direction according to the incident angle of the sensor using the following equation:

$$
\mathrm{d}_{u}=\mathrm{d}_{l o s} / \cos \theta
$$

where the $\theta$ represents the incidence angle and $\mathrm{d}_{u}$ and $\mathrm{d}_{l o s}$ are the deformations in the vertical and LOS directions, respectively. The vertical deformation rate calculated from the two sets of Envisat data was linearly fitted (Figure 7a) and the correlation coefficient was 0.88 . The difference in the vertical deformation rate values of the common pixels between the two sets of Envisat ASAR data is shown in Figure $7 \mathrm{~b}$. The absolute value of the difference between the two sets of data, which was less than $5 \mathrm{~mm}$, was $95 \%$. These two results have a high degree of consistency, which also demonstrates the reliability of our results.

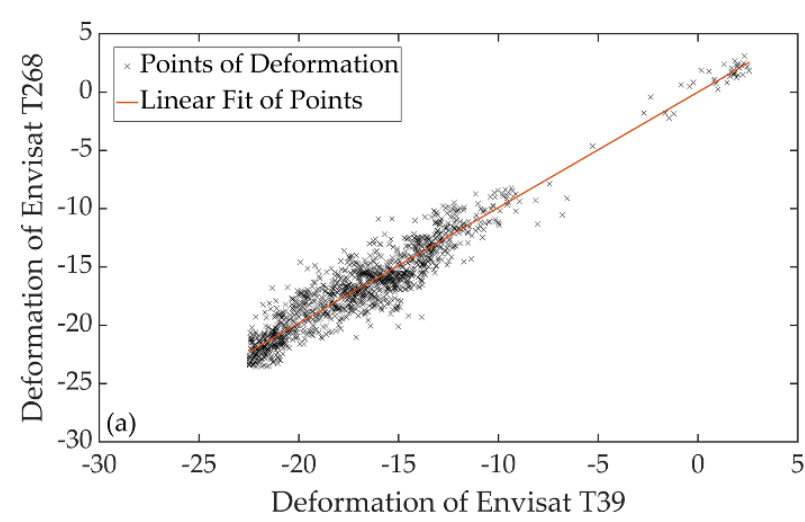

Figure 7. Internal accuracy verification. (a) Scatter plot and linear fit of deformation rate for the two sets of results, and (b) difference between the two sets of results in the vertical direction. 


\subsection{Land Subsidence Analysis}

Through the deformation zone, Profile S1 was created to observe the relationship between the settlement funnel and the undulation of the bedrock, as shown in Figure 8. The surface deformation rate and bedrock depth along S1 were extracted as shown in Figure 9a. We can intuitively see that compared with shallow areas, the land subsidence is more serious where the bedrock is deeply buried. In other words, the trend of the deformation field was in good agreement with the undulation of the bedrock. The distribution of subsidence areas was spatially consistent with the distribution of ancient river channels (Figure 8). This verifies that fluctuations in bedrock control the formation and development of ground subsidence disasters.

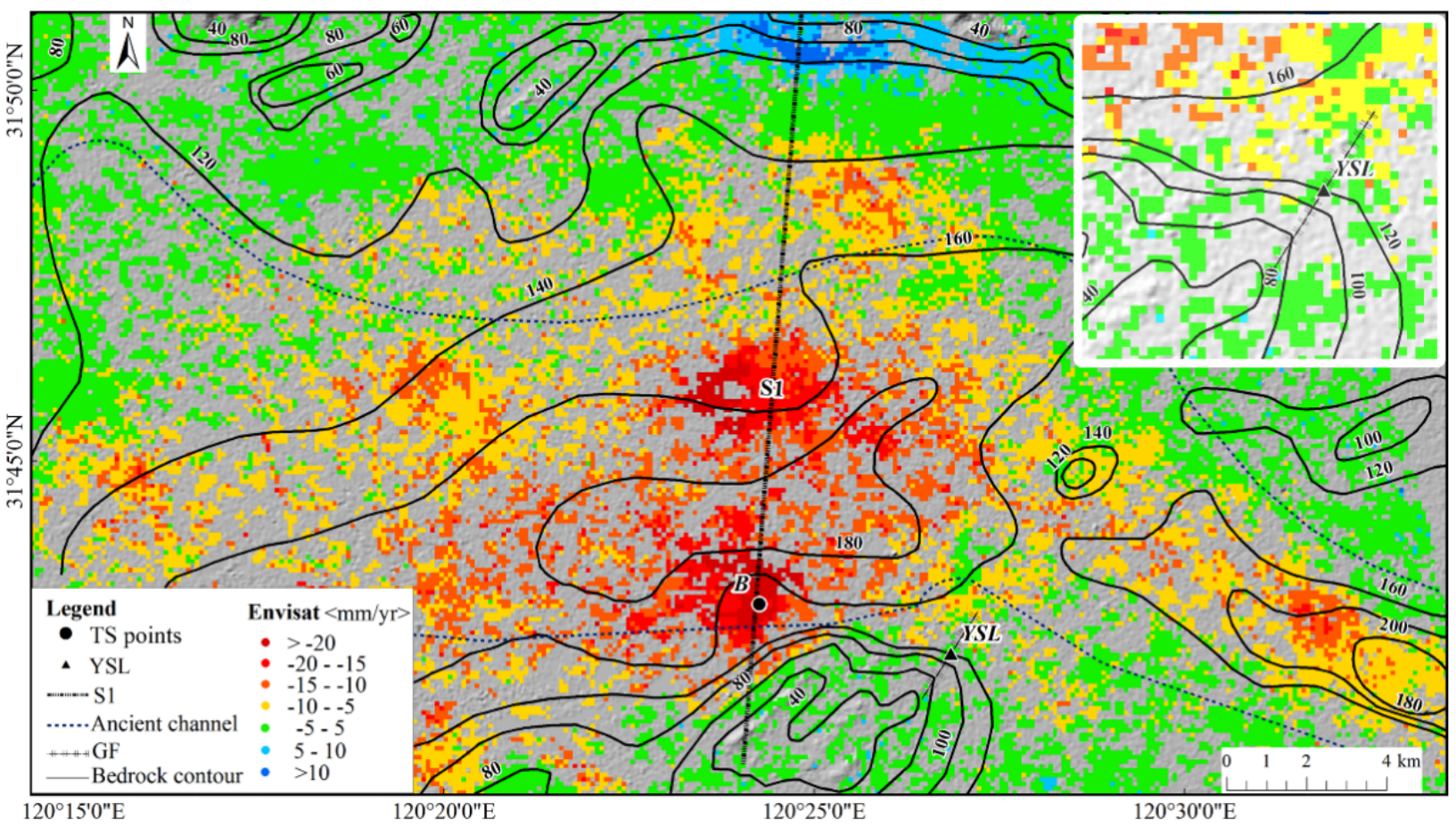

Figure 8. The land subsidence field in southern Jiangyin city (the small figure in the upper right corner is an enlarged view of the ground fissure area).
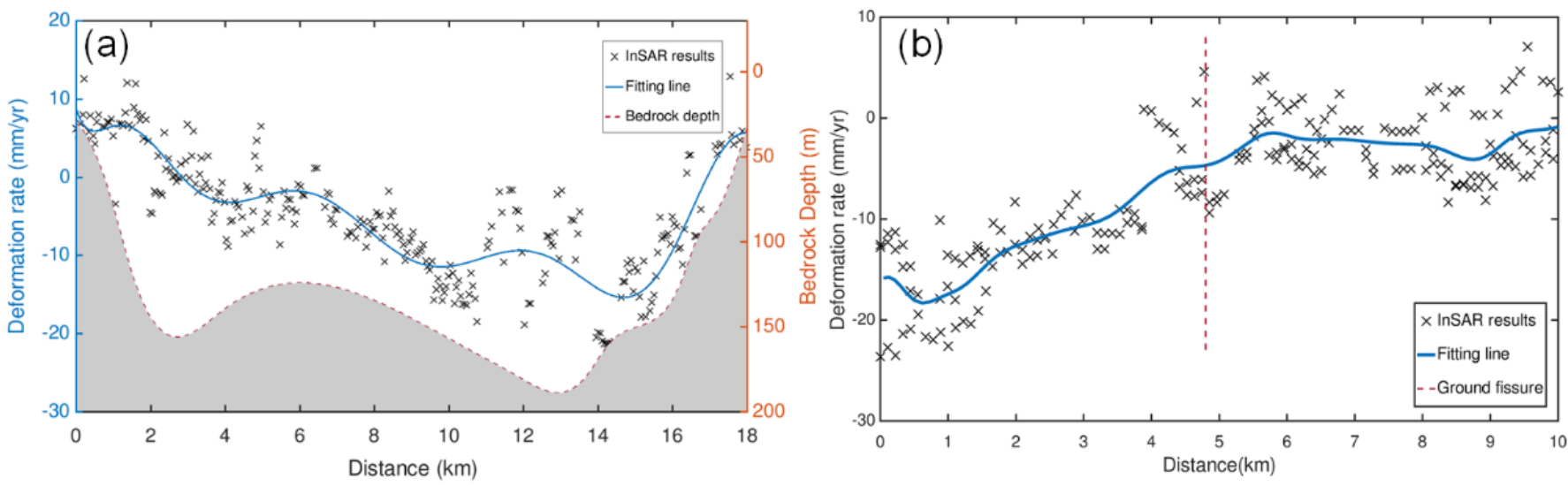

Figure 9. Profile analysis. (a) Comparison of InSAR results with the variation of bedrock undulations along profile S1 whose position is indicated in Figure 8. (b) Comparison of deformation information on both sides of the ground fissure. 


\subsection{Ground Fissure Analysis}

The first GF in the Su-Xi-Chang plain area was formed in 1989, and GF disasters increased every year before 2004 [49]. The specific spatial distribution of GFs in this area is disarranged and closely related to paleogeography. Among the many paleo-geographic factors, the bedrock buried hill is the dominant one [28]. According to existing investigations, GFs in the YSL, GM Village, corresponding to the bedrock ridge in the area, have the following similarities with other GFs in Changzhou and Wuxi: the geological background is similar, the ground subsidence is severe in places where the GF disasters occurred and the time of their occurrence was similar [22,28]. Therefore, only representative and typical YSL GFs were analyzed, and numerical simulations and analyses were carried out.

The GFs in the YSL are shown as clusters of GFs, with the main cracks trending at $48^{\circ}$, approximately $100 \mathrm{~m}$ in length, and $20 \mathrm{~m}$ in width [28]. To analyze the causes and development of GFs in this area, we extracted InSAR monitoring data within a range of 5 $\mathrm{km}$ on each side of the GF. As the GF is too small relative to the study area, we used the black dashed line to indicate the location and direction of the GF (Figure 9b).

In Figure 9b, the black ' $x$ ' symbol represents the InSAR results, the blue solid line is obtained by fitting the InSAR results, and the red dashed line represents the location of the GF. We can intuitively see that the gradient of the settlement rate on both sides of the GF has changed significantly, the footwall of the GF is relatively stable (i.e., the part on the right side of the dashed line), and the settlement rate is relatively slow, approximately 5 $\mathrm{mm}$ /year. The settlement rate of the hanging wall is relatively large (i.e., the part on the left side of the dotted line)—above $15 \mathrm{~mm} /$ year-and locally exceeds $20 \mathrm{~mm} /$ year. The monitoring results proved that differential settlement led to the development of the GFs.

\section{Deformation Modeling}

Long-term groundwater exploitation is an essential factor in inducing GFs. Fluctuation of the bedrock surface is the internal cause of the birth of GFs. Excessive exploitation of groundwater is a direct condition [13,25]. To understand the impact of pumping activities on GFs above bedrock undulations, we conducted a numerical simulation of the process using the Moore-Coulomb model with the FLAC3D software.

\subsection{Model Establishment}

We simulated the influence of groundwater extraction activities on the formation and development of GFs based on the bedrock bulge. First, a simple model was built using the built-in extrusion module of FLAC3D software. The model was $400 \mathrm{~m}$ in length, $150 \mathrm{~m}$ in depth and $250 \mathrm{~m}$ in height. The undulations of the buried hill in the model were designed based on an existing geological map (Figure 10a). The pumping well was set above the highest point of the bedrock. The depth of the pumping well was set to $90 \mathrm{~m}$, and the pumping strength was $15 \mathrm{~m}^{3} / \mathrm{s}$. As shown in Figure 10b, the model was divided into four layers: the first layer was the loess layer and the second was the clay layer; the third one was composed of sand and the fourth was bedrock. Due to the lack of detailed geological exploration data in this area, we designed the specific parameters of each soil layer in our experimental model (Table 2), referring to the published research results [50-52] and investigation reports $[13,28,35]$ in this area. Figure $10 \mathrm{c}$ shows the displacement boundary conditions. Blue, green and red represent fixed $X$-direction, $Y$-direction and $Z$-direction displacements, respectively. 

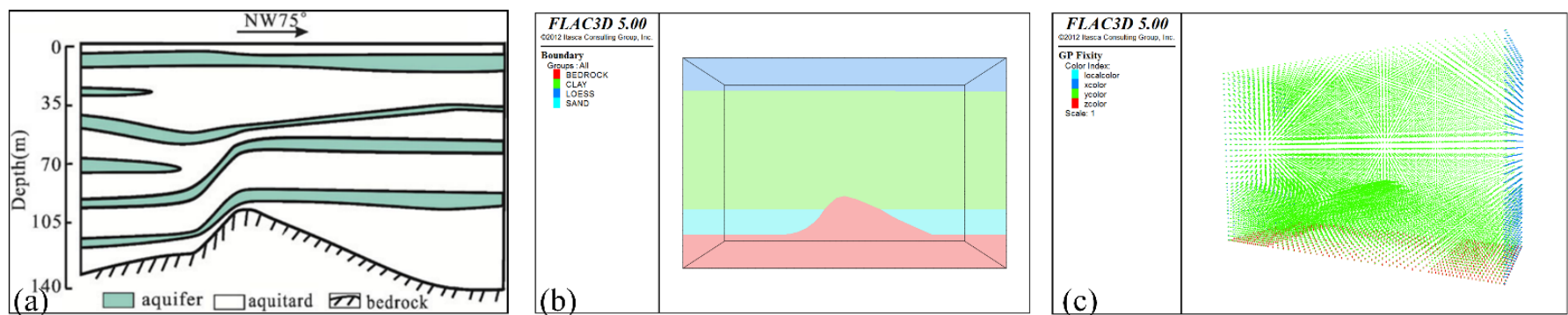

Figure 10. (a) Stratigraphic cross section. (c) Boundary condition setting.

Table 2. Physical parameters of each soil layer.

\begin{tabular}{ccccc}
\hline \multirow{2}{*}{ Parameter } & \multicolumn{3}{c}{ Value } \\
\cline { 2 - 5 } & Loess & Clay & Sand & Bedrock \\
\hline Cohesion, $c(\mathrm{kPa})$ & 35 & 800 & 39 & 4620 \\
Dilation angle, $\Psi\left(^{\circ}\right)$ & 14 & 9.5 & 12.5 & 22.5 \\
Internal friction angle, $\varphi\left(^{\circ}\right)$ & 28 & 19 & 25 & 45 \\
Tensile strength, $T(\mathrm{kPa})$ & 0 & 0 & 400 & 4500 \\
Permeability coefficient, $k$ & $5.1 \times 10^{-10}$ & $0.3 \times 10^{-7}$ & $2.04 \times 10^{-9}$ & $1.02 \times 10^{-15}$ \\
$\left(\mathrm{~m}^{2} / \mathrm{Pa} / \mathrm{s}\right)$ & 40 & 150 & 120 & 5400 \\
Elastic modulus, $\mathrm{E}(\mathrm{MPa})$ & 0.48 & 0.38 & 0.4 & 0.1 \\
Porosity, $n$ & 0.35 & 0.3 & 0.23 & 0.29 \\
Poisson's ratio, $v$ & & &
\end{tabular}

The bulk modulus $\mathrm{K}$ and shear modulus $\mathrm{G}$ must be calculated from the elastic modulus E and Poisson's ratio v:

$$
\begin{aligned}
& \text { bulk modulus : } K=\frac{E}{3(1-2 v)} \\
& \text { shear modulus: } G=\frac{E}{2(1+v)}
\end{aligned}
$$

\subsection{State of Equilibrium before Pumping}

Figure 11a shows the initial stress field, and the color scale on the left shows the magnitude of the stress. The negative values indicate compressive stress and the positive values indicate tensile stress. It is the effect of pressure accumulation caused by the action of gravity on the rock and soil that causes the initial stresses to all be compressive stresses. Furthermore, we found that the vertical downward pressure on the left side of the ridge was greater than that on the right. This is because the overlying soil layers on the left side of the bedrock are more affected by gravity than those on the right side and have a tendency to produce differential settlement. This also shows that undulation of the bedrock is the internal cause of the GFs.

The same conclusion from the initial displacement field can also be obtained. (Figure 11b,c). The $X$-direction displacement on the left side of the bedrock protrusion was negative, indicating that the soil on the left had a displacement away from the bedrock protrusion. Similarly, the soil on the right was displaced away from the bedrock protrusion. The $Z$-direction displacement of the soil on both sides of the bedrock protrusion was negative, which indicates a downward displacement. Combining the displacement in the $X$ and $Z$ directions, the ground above the bedrock protrusion will be an area highly prone to GFs, which also verifies that the undulation of the bedrock surface is the internal cause of GFs.

Figure 11d shows the initial seepage field; the color scale on the left indicates the amount of seepage flow and the direction of the arrow indicates the direction of seepage. It shows that the seepage in the upper soil was mainly concentrated in the lower soil, indicating that the movement of pore water in the middle and upper layers is less affected 
by external forces. Moreover, the seepage flow on the upper surface of the bedrock was almost zero, which indicates that the bedrock has a blocking effect on the plane distribution of the aquifer. However, this isolation was not absolute, and a small amount of pore water was still observed to be moving along the model boundary.
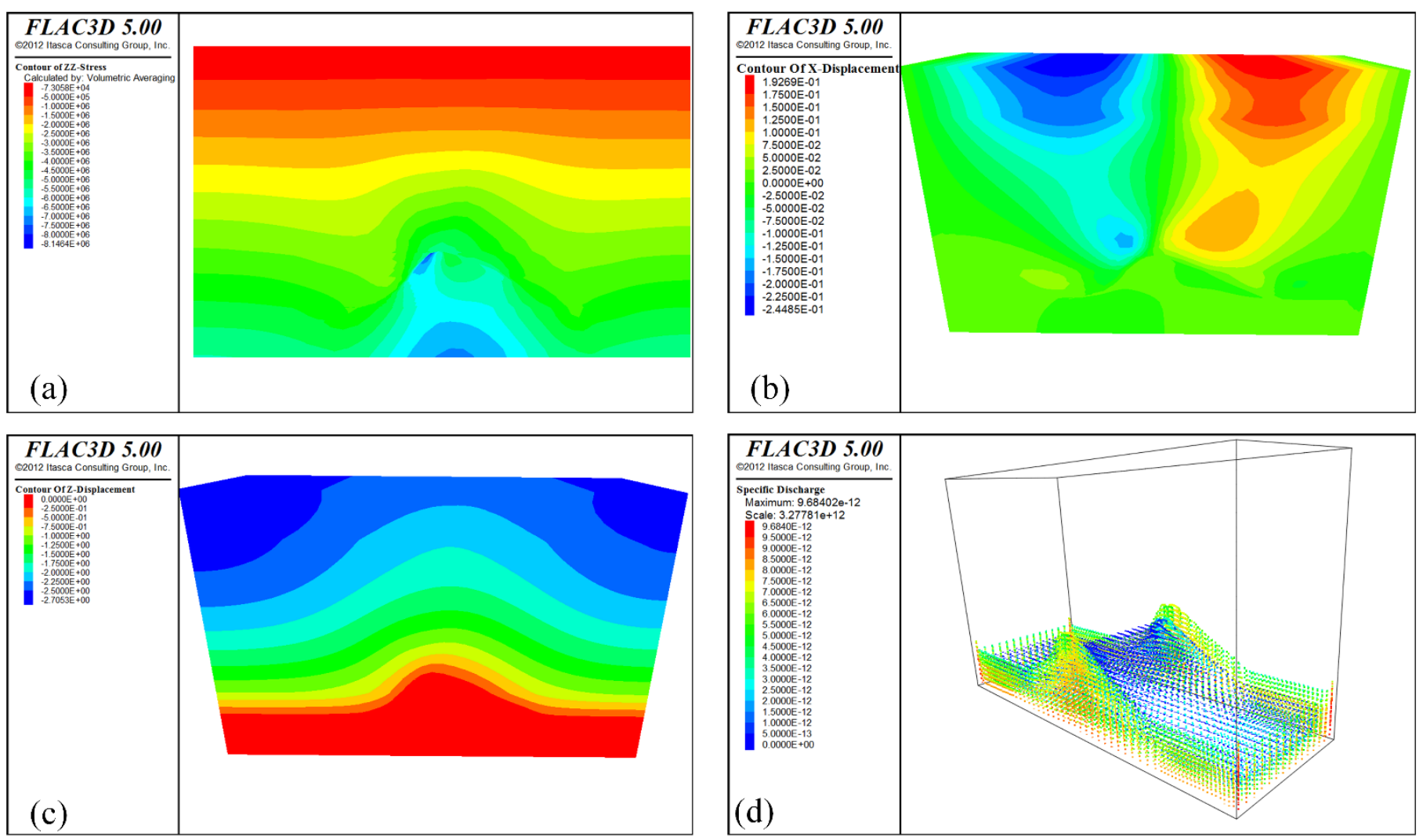

Figure 11. The initial state of equilibrium. (a) Initial stress field. (b) Initial displacement field (X direction). (c) Initial displacement field ( $Z$ direction). (d) Initial seepage field.

\subsection{Pumping Simulation}

Figure $12 \mathrm{a}, \mathrm{b}$ show the stress distribution during the pumping activity. The magnitude of the $x$ - and $z$-directions stress is increased compared with the initial equilibrium state, indicating that the pumping activity causes the stress on the soil particles around the well to change significantly. Figure 12c shows the total displacement, with the arrow indicating the direction of the displacement, indicating that pumping activities have aggravated the surface deformation near the pumping well. Figure $12 \mathrm{~d}$ shows the displacement component in the X-direction; we found that the soil was displaced away from the bedrock bridge and that the deformation area on the left side of the buried hill is larger than that on the right side, indicating that the top of the bedrock ridge has become an area prone to ground fissures. Figure 12e shows that the vertical compression around the pumping well is more serious, and the settlement on the left side is greater at the same level. As is shown in Figure 12f, in the seepage field in an equilibrium state after the pumping activity, it can be seen from the color scale on the left that the maximum seepage flow rate was lower than that in the initial seepage field, indicating that decreases in the aquifer water and the compression of the soil layer reduced the seepage velocity after the pumping.

According to the principle of effective stress, when the pore water pressure changes, the porosity between the soil skeleton increases after the pore water is discharged. Due to the large horizontal seepage in the horizontal direction of the pumped aquifer, the seepage force will drive the solid particles to migrate and compact, which is macroscopically manifested as the horizontal displacement of the formation. In the vertical direction, the 
aquifer loses water. When the total stress remains unchanged, the stress borne by the pore water decreases, and the stress borne by the soil skeleton will increase, resulting in the increase of effective stress, which will compress the soil particles downward to decrease the porosity, form vertical displacement in the stratum, and macroscopically show vertical settlement; the seepage activity of the pore water in the underlying soil was restrained. Therefore, the seepage rate was lower than that before pumping.
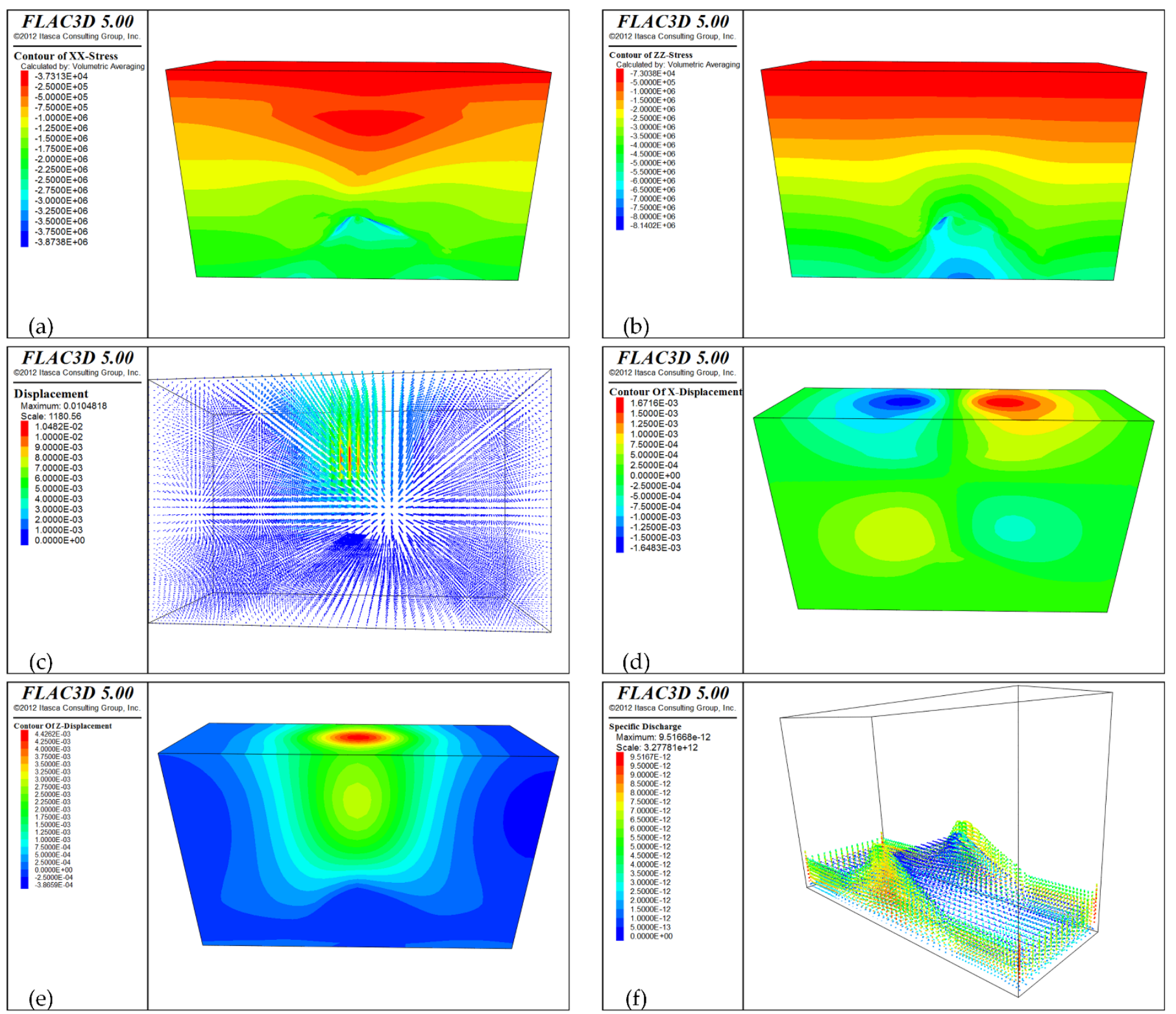

Figure 12. Distribution of stress field, deformation field, and seepage field after pumping. (a) Stress field distribution ( $x$ direction). (b) Stress field distribution ( $z$ direction). (c) Total displacement. (d) Displacement field distribution ( $x$ direction). (e) Displacement field distribution ( $Z$ direction). (f) Pumping seepage field.

\section{Discussion}

\subsection{Deformation and Geological Factors}

The Su-Xi-Chang area has suffered severe land subsidence due to the long-term overexploitation of groundwater. Differences in bedrock undulations, quaternary sedimentary structures, and hydrogeological conditions are the internal conditions that trigger GF disasters. The long-term excessive exploitation of groundwater is an external factor that induces 
GF disasters. The excessive extraction of groundwater by human activities causes the compression of soil particles, forming an underground sedimentation funnel and resulting in ground subsidence [30].

By comparing the relationship between bedrock undulations and the InSAR results, we can intuitively see that bedrock undulations control land subsidence. In addition, the settlement field in southern JY had a large degree of correlation with the distribution of ancient river channels (Figure 8). The monitoring results from 2007 to 2010 showed that although the extraction of groundwater was banned in 2005, subsidence was still serious and rapidly developing. However, with the implementation of water prohibition measures, land subsidence in most areas of the Su-Xi-Chang area improved. By observing the InSAR results from 2018 to 2021, we found that land subsidence in the Su-Xi-Chang area has stabilized as a whole, and there has been an obvious rebound in some areas.

\subsection{Ground Fissure Activity and Pumping}

Field investigations have shown that the YSL GF is located just at the uplift of the bedrock, and because of the uneven distribution of the aquifer, under the action of pumping water in this area, there is too much water loss in the thick aquifer and less water loss in the thin aquifer, resulting in uneven differential settlement $[22,28]$. Subsequently, GF disasters occurred in this area.

Through the monitoring results of the InSAR data, we intuitively found that the area had obvious differential settlements on both sides of the GF. The footwall of the GF is relatively stable, but it still has a settlement rate of $5 \mathrm{~mm} /$ year. The settlement of the hanging wall was more serious, with a deformation rate difference of nearly $15 \mathrm{~mm} /$ year with the footwall; this verifies the conclusions of the aforementioned field investigation. Through the analysis of deformation rate from 2018 to 2021, the difference of overall deformation rate in southern Jiangyin is less than $5 \mathrm{~mm}$ /year (Figure $5 \mathrm{~b}$ ), and the ground deformation has been basically restrained. Due to the small deformation magnitude, the current situation of ground fissures is not analyzed.

Land subsidence and the formation of GFs in this area are mainly controlled by bedrock and affected by pumping activities, which accelerate the process of land subsidence. Through the process of FLAC3D numerical simulation and analysis, we found that because of the shape of the bedrock undulation in the area and the uneven thickness of the soil on both sides of the bedrock, the soil tends to compress and become uneven under the action of its own weight, and there is a potential danger of uneven settlement. Pumping activities accelerated and aggravated this process, leading to GF disasters.

\section{Conclusions}

To analyze the land subsidence and GF activities in the Su-Xi-Chang area, we obtained the ground deformation characteristics at different time periods using the time-series InSAR technique. The maximum land subsidence rate exceeded $25 \mathrm{~mm} /$ year from 2007 to 2010. By extracting the characteristic points from the three subsidence centers in the $\mathrm{Su}-\mathrm{Xi}-\mathrm{Ch}$ ang area, we found that land subsidence in Suzhou was relatively well controlled. The land subsidence in Changzhou and Wuxi was serious, and the cumulative subsidence at the characteristic points exceeded $75 \mathrm{~mm}$. It is verified that even after the prohibition of groundwater extraction in this area, the land subsidence disaster was still serious in the following years owing to the lag effect of aquifer recovery.

Through the comparison between the deformation rate and the corresponding bedrock depth, it is concluded that areas with a relatively thick soil layer have larger compressible space, and so the corresponding deformation rate may also be larger. We also found that formation and development are related to the spread of the ancient channel. By comparing the deformation rate of the hanging and foot walls of the GF, we proved that the direct cause of the ground fissure is differential settlement (Figure 9). Land subsidence in most areas of the Su-Xi-Chang area has decelerated, and a large area of rebound has occurred 
from 2018 to 2021; the rebound rate has been approximately $10 \mathrm{~mm} /$ year. This verifies the effectiveness of the prohibition of groundwater extraction.

Through the simulation of pumping activities using FLAC3D, we proved that at the bedrock buried hill, the soil is prone to ground fissure disaster under the influence of its own gravity. By comparing the equilibrium state before and after pumping activities, we found that pumping activities accelerate and aggravate the process of land subsidence. Pumping activity leads to the release of water from soil particles, and the soil layer compresses and consolidates with increases in the effective stress of soil particles. Due to the uneven distribution of the soil layer caused by the existence of bedrock buried hill, differential settlement easily occurs in the process of pumping, which makes the upper part of bedrock buried hill an area prone to ground fissures.

Unfortunately, we have not been able to obtain more detailed geological data on this area from public data, such as the thickness of aquifers and a larger range of bedrock undulations. Therefore, we were not able to perform further analyses in some areas. Furthermore, when FLAC3D is used for numerical simulations, only simple models can be built. Hence, there was a difference between the simulated and real results. These limitations necessitate that in-depth research be conducted in the future.

Author Contributions: C.Y. conceived and designed the experiments; C.Y. and S.L. performed the experiments and drafted the manuscript; Z.H., Q.Z., T.L. and C.Z. contributed to the discussion of the InSAR results. All authors have read and agreed to the published version of the manuscript.

Funding: This research was funded by the National Natural Science Foundation of China (NSFC), (Nos. 42174032, 41731066).

Institutional Review Board Statement: Not applicable.

Informed Consent Statement: Not applicable.

Data Availability Statement: The sentinel 1 data in the experiment were obtained by ESA Copernicus data hub. SRTM1 data can be downloaded at https://earthexplorer.usgs.gov/ (accessed on 28 December 2021).

Acknowledgments: We also thank JPL/Caltech for the ROI PAC, TU-Delft for DORIS, and Andy Hooper for StaMPS. We are grateful for the helpful corrections and suggestions of the anonymous reviewers.

Conflicts of Interest: The authors declare no conflict of interest.

\section{References}

1. Chaussard, E.; Wdowinski, S.; Cabral-Cano, E.; Amelung, F. Land subsidence in central Mexico detected by ALOS InSAR time-series. Remote Sens. Environ. 2014, 140, 94-106. [CrossRef]

2. Hernandez-Marin, M.; Pacheco-Martinez, J.; Ramirez-Cortes, A.; Burbey, T.J.; Ortiz-Lozano, J.A.; Zermeno-de-Leon, M.E.; Guinzberg-Velmont, J.; Pinto-Aceves, G. Evaluation and analysis of surface deformation in west Chapala basin, central Mexico. Environ. Earth Sci. 2014, 72, 1491-1501. [CrossRef]

3. Ojha, C.; Werth, S.; Shirzaei, M. Recovery of aquifer-systems in southwest US following 2012-2015 drought: Evidence from InSAR, GRACE and groundwater level data. J. Hydrol. 2020, 587, 16. [CrossRef]

4. El Kamali, M.; Papoutsis, I.; Loupasakis, C.; Abuelgasim, A.; Omari, K.; Kontoes, C. Monitoring of land surface subsidence using persistent scatterer interferometry techniques and ground truth data in arid and semi-arid regions, the case of Remah, UAE. Sci. Total Environ. 2021, 776, 11. [CrossRef] [PubMed]

5. Peng, J.B.; Xu, J.S.; Ma, R.Y.; Wang, F.Y. Characteristics and mechanism of the Longyao ground fissure on North China Plain, China. Eng. Geol. 2016, 214, 136-146. [CrossRef]

6. Xu, J.; Meng, L.; An, H.; Wang, L. The bending mechanism of Anping ground fissure in the Hebei Plain, North China. Environ. Earth Sci. 2015, 74, 6859-6870. [CrossRef]

7. Chen, B.B.; Gong, H.L.; Chen, Y.; Lei, K.C.; Zhou, C.F.; Si, Y.; Li, X.J.; Pan, Y.; Gao, M.L. Investigating land subsidence and its causes along Beijing high-speed railway using multi-platform InSAR and a maximum entropy model. Int. J. Appl. Earth Obs. Geoinf. 2021, 96, 15. [CrossRef]

8. Li, M.-G.; Chen, J.-J.; Xu, Y.-S.; Tong, D.-G.; Cao, W.-W.; Shi, Y.-J. Effects of groundwater exploitation and recharge on land subsidence and infrastructure settlement patterns in Shanghai. Eng. Geol. 2021, 282, 105995. [CrossRef]

9. Xiong, Z.M.; Wang, Y.W.; Chen, X.; Xiong, W.Y. Seismic behavior of underground station and surface building interaction system in earth fissure environment. Tunn. Undergr. Space Technol. 2021, 110, 14. [CrossRef] 
10. Cigna, F.; Tapete, D. Sentinel-1 big data processing with P-SBAS InSAR in the geohazards exploitation platform: An experiment on coastal land subsidence and landslides in Italy. Remote Sens. 2021, 13, 885. [CrossRef]

11. Fabris, M. Monitoring the coastal changes of the Po River delta (Northern Italy) since 1911 using archival cartography, multitemporal aerial photogrammetry and LiDAR data: Implications for coastline changes in 2100 AD. Remote Sens. 2021, 13, 529. [CrossRef]

12. Wang, J. Theory and Application of Ground Fissures and Their Disasters; Shaanxi Science and Technology Press: Xi'an, China, 2000.

13. Xu, J.; Peng, J.; An, H. Experimental study on Su-Xi-Chang earth fissures induced by repeated groundwater pumping and impounding. Geomat. Nat. Hazards Risk 2019, 10, 2051-2068. [CrossRef]

14. Hu, J.P. A Study on the Land Subsidence Effect After Prohibiting Extraction of Ground Water in Suzhou-Wuxi-Changzhou Area. Ph.D. Thesis, Nanjing University, Nanjing, China, 2011.

15. Budhu, M. Earth Fissure formation from the mechanics of groundwater pumping. Int. J. Geomech. 2011, 11, 1-11. [CrossRef]

16. Jia, Z.J.; Qiao, J.W.; Peng, J.B.; Lu, Q.Z.; Xia, Y.Y.; Zang, M.D.; Wang, F.Y.; Zhao, J.Y. Formation of ground fissures with synsedimentary characteristics: A case study in the Linfen Basin, northern China. J. Asian Earth Sci. 2021, 214, 104790. [CrossRef]

17. Nespoli, M.; Cenni, N.; Belardinelli, M.E.; Marcaccio, M. The interaction between displacements and water level changes due to natural and anthropogenic effects in the Po Plain (Italy): The different point of view of GNSS and piezometers. J. Hydrol. 2021, 596, 126112. [CrossRef]

18. Tiwari, A.; Narayan, A.B.; Dwivedi, R.; Swadeshi, A.; Pasari, S.; Dikshit, O. Geodetic investigation of landslides and land subsidence: Case study of the Bhurkunda coal mines and the Sirobagarh landslide. Surv. Rev. 2020, 52, 134-149. [CrossRef]

19. Zhang, Y.Q.; Gong, H.L.; Gu, Z.Q.; Wang, R.; Li, X.J.; Zhao, W.J. Characterization of land subsidence induced by groundwater withdrawals in the plain of Beijing city, China. Hydrogeol. J. 2014, 22, 397-409. [CrossRef]

20. Damoah-Afari, P. Detecting Ground Settlement of Megacities Using InSAR Techniques. Ph.D. Thesis, Hong Kong Polytechnic University, Hong Kong, China, 2009.

21. Wan, J.; Bin, L.I.; Tan, C.; Zhang, P.; Feng, C. Characteristics and mechanism of earth fissures in China: A case study of Fenhe River-Weihe River basin, Hebei plain and Suzhou-Wuxi-Changzhou plain. J. Geol. Rev. 2019, 65, 1383-1396. [CrossRef]

22. Jian-Qiang, W.U.; Zhou, G.J.; Shu-Liang, W.U.; Wei, L.I.; Ming, W. Research on earth fissures in Guangming Village of Wuxi City. J. Geol. 2013, 37, 203-207.

23. Shi, X.-Q.; Xue, Y.-Q.; Ye, S.-J.; Wu, J.-C.; Zhang, Y.; Yu, J. Characterization of land subsidence induced by groundwater withdrawals in Su-Xi-Chang area, China. Environ. Geol. 2007, 52, 27-40. [CrossRef]

24. Bu, J.W.; Sun, Z.Y.; Ma, R.; Liu, Y.D.; Gong, X.L.; Pan, Z.; Wei, W.H. Shallow groundwater quality and its controlling factors in the $\mathrm{Su}-\mathrm{Xi}$-Chang region, Eastern China. Int. J. Environ. Res. Public Health 2008, 17, 1267. [CrossRef] [PubMed]

25. Wang, G.-Y.; Zhu, J.-Q.; Zhang, D.; Wu, J.-Q.; Yu, J.; Gong, X.-L.; Gou, F.-G. Land subsidence and uplift related to groundwater extraction in Wuxi, China. Q. J. Eng. Geol. Hydrogeol. 2020, 53, 609-619. [CrossRef]

26. Gu, K.; Shi, B.; Liu, C.; Jiang, H.; Li, T.; Jinghong, W. Investigation of land subsidence with the combination of distributed fiber optic sensing techniques and microstructure analysis of soils. Eng. Geol. 2018, 240, 34-47. [CrossRef]

27. Zhao, W.-T.; Li, L. The mechanism of land subsidence and its prevention measures in Suzhou-Wuxi-Changzhou area. Chinese. J. Geol. Hazard Control 2009, 20, 88-93. [CrossRef]

28. Gu, C. Experimental Study on the Development and Evolution of Ground Fissures Caused by Extraction of Groundwater in Suzhou-Wuxi-Changzhou Region. Master's Thesis, China University of Mining and Technology, Xuzhou, China, 2017.

29. Hooper, A.; Bekaert, D.; Spaans, K.; Arikan, M. Recent advances in SAR interferometry time series analysis for measuring crustal deformation. Tectonophysics 2012, 514-517, 1-13. [CrossRef]

30. Wang, G.-Y.; You, G.; Zhu, J.-Q.; Yu, J.; Gong, X.-L.; Wu, J.-Q. Investigations of Changjing earth fissures, Jiangyin, Jiangsu, China. Environ. Earth Sci. 2016, 75, 502. [CrossRef]

31. Wu, Z.; Yu, Q.; Zhang, Y. Forming process of earth fissure hazard in the Suzhou-Wuxi-Changzhou area. Hydrogeol. Eng. Geol. 2003, 30, 67-72. [CrossRef]

32. Yang, Y. The Influence of the Land Subsidence Around Su-Xi-Chang Area to the Bejing-Shanghai High-Speed Railway. Master's Thesis, Southwest Jiaotong University, Nanjing, China, 2012.

33. Yuan, Y.; Zhang, T. Prediction of ground fissures risk in Suxichang area based on principal component analysis and support vector machine. J. Catastrophol. 2019, 34, 57-63. [CrossRef]

34. Chen, Y.; Zhao, W.; Huang, Y.; Jia, P. Investigation of land subsidence based on the column element settlement model in a soft-soil area. Geofluids 2019, 2019, 9530135. [CrossRef]

35. Liu, Y.; Zhang, D.; Wang, G.Y.; Liu, C.; Zhang, Y. Discrete element method-based prediction of areas prone to buried hill-controlled earth fissures. J. Zhejiang Univ. Sci. A 2019, 20, 794-803. [CrossRef]

36. Gabriel, A.K.; Goldstein, R.M.; Zebker, H.A. Mapping small elevation changes over large areas: Differential radar interferometry. J. Geophys. Res. 1989, 94, 9183-9191. [CrossRef]

37. Zebker, H.A.; Rosen, P.A.; Goldstein, R.M.; Gabriel, A.; Werner, C.L. On the derivation of coseismic displacement fields using differential radar interferometry: The Landers earthquake. J. Geophys. Res. 1994, 99, 19617-19634. [CrossRef]

38. Rosen, P.A.; Henley, S.; Peltzer, G.; Simons, M. Updated repeat orbit interferometry package released. Eos Transact. Am. Geophys. Union 2013, 85, 47. [CrossRef]

39. Kampes, B.M. Radar Interferometry: Persistent Scatterer Technique; Springer: Dordrecht, The Netherlands, 2006. 
40. Hooper, A.; Bekaert, D.; Spaans, K. StaMPS/MTI Manual Version 3.3 b1; University of Leeds: Leeds, UK, 2013.

41. Likoka, A.S. Atmospheric effects estimation on SAR images using a pure statistical method. In Computational Imaging II, Proc. SPIE 10222; SPIE: Bellingham, WA, USA, 2017. [CrossRef]

42. Budhu, M. Mechanics of earth fissures using the Mohr-Coulomb failure criterion. Environ. Eng. Geosci. 2008, 14, 281-295. [CrossRef]

43. Martinez-Noguez, I.; Hinkelmann, R. Land subsidence caused by a single water extraction well and rapid water infiltration. In Prevention and Mitigation of Natural and Anthropogenic Hazards due to Land Subsidence; Daito, K., Galloway, D., Eds.; Copernicus Gesellschaft Mbh: Gottingen, Germany, 2015; pp. 33-38. [CrossRef]

44. Yang, C.; Zhang, F.; Liu, R.; Hou, J.; Zhao, C. Ground deformation and fissure activity of the Yuncheng Basin (China) revealed by multiband time series InSAR. Adv. Space Res. 2020, 66, 490-504. [CrossRef]

45. Qu, F.; Zhang, Q.; Lu, Z.; Zhao, C.; Yang, C.; Zhang, J. Land subsidence and ground fissures in Xi'an, China 2005-2012 revealed by multi-band InSAR time-series analysis. Remote Sens. Environ. 2014, 155, 366-376. [CrossRef]

46. Bechor, N.; Zebker, H.A. Measuring two-dimensional movements using a single InSAR pair. Geophys. Res. Lett. 2006, 33, 275-303. [CrossRef]

47. Samsonov, S.; Tiampo, K. Analytical optimization of a DInSAR and GPS dataset for derivation of three-dimensional surface motion. IEEE Geosci. Remote Sens. Lett. 2006, 3, 107-111. [CrossRef]

48. Wright, T.J.; Parsons, B.E.; Lu, Z. Toward mapping surface deformation in three dimensions using InSAR. Geophys. Res. Lett. 2004, 31, L01607. [CrossRef]

49. Wang, Y.; Shujun, Y.E.; Jun, Y.U.; Gong, X.; Hydrosciences, D.O. Features and mechanisms of earth fissures induced groundwater withdrawal in China. Geol. J. China Univ. 2016, 22, 741. [CrossRef]

50. Li, C.-Q.; Liang, Q.G.; Xu-Yang, W.U.; Wang, L.L.; Shan-Chang, X.U. Study on the test of tensile strength of remolded loess. China Earthq. Eng. J. 2014, 233-238, 248. [CrossRef]

51. Yao, Y.; Zhang, B.; Zhu, J. Behaviors, constitutive models and numerical simulation of soils. Tumu Gongcheng Xuebao/China Civil Eng. J. 2012, 45, 127-150. [CrossRef]

52. Zhang, Y. Study on The Engineering Mechanic Properties of Loess-Paleosol. Master's Thesis, Xi'an University of Architecture and Technology, Xi'an, China, 2011. 